\title{
Seleção de espécies bioindicadoras para os herbicidas trifloxysulfuron-sodium e pyrithiobac-sodium ${ }^{1}$
}

\author{
Bioindicators species selecting to trifloxysulfuron-sodium and pyrithiobac-sodium \\ herbicides
}

\author{
Naiara Guerra ${ }^{2}$, Rubem Silvério de Oliveira Júnior ${ }^{3}$, Jamil Constantin ${ }^{3}$, \\ Antonio Mendes de Oliveira Neto ${ }^{2}$, Hugo de Almeida Dan ${ }^{2}$, Diego Gonçalves Alonso ${ }^{2}$, \\ Talita Mayara de Campos Jumes ${ }^{4}$
}

Resumo - O uso de espécies bioindicadoras é muito comum em estudos do comportamento de herbicidas no solo. Trifloxysulfuron-sodium e pyrithiobac-sodium são herbicidas recomendados para o controle de plantas daninhas em pós-emergência da cultura do algodão, e apresentam potencial de "carryover" para culturas semeadas em sucessão. O trabalho teve como objetivo avaliar a susceptibilidade de espécies a dosagens dos herbicidas trifloxysulfuron-sodium e pyrithiobac-sodium, buscando selecionar plantas que possam ser utilizadas no monitoramento de baixas concentrações destes herbicidas no solo. Dois ensaios foram conduzidos simultaneamente em delineamento inteiramente casualizado, dispostos em esquema fatorial $4 \times 5$, constituídos por quatro espécies utilizadas como bioindicadoras (pepino [Cucumis sativus], soja [Glycine max], milho [Zea mays] e feijão [Phaseolus vulgaris] e cinco dosagens dos herbicidas (trifloxysulfuronsodium $0 ; 0,94 ; 1,87 ; 3,75$ e $7,5 \mathrm{~g} \mathrm{ha}^{-1}$ e pyrithiobac-sodium $0 ; 8,75 ; 17,5 ; 35$ e $70 \mathrm{~g} \mathrm{ha}^{-1}$ ) aplicados em pré-emergência, antes da semeadura dos bioindicadores. Aos 21 dias após a aplicação, as plantas foram avaliadas quanto à fitointoxicação, altura e acúmulo de massa da parte aérea, calculando-se o $\mathrm{I}_{50}$ (dose necessária para redução de $50 \%$ da variável analisada), visando comparar a sensibilidade das espécies aos herbicidas. Concluiu-se que o pepino e o milho comportaram-se como as espécies mais sensíveis aos herbicidas trifloxysulfuron-sodium e pyrithiobac-sodium, tendo potencial para utilização em bioensaios com esses herbicidas.

Palavras-chave: Bioensaios, inibidores de ALS, pepino, comportamento no solo.

\begin{abstract}
Using bioindicator species is really common in studies concerning herbicides behavior in soil. Trifloxysulfuron-sodium and pyrithiobac-sodium are herbicides recommended for post-emergence weed control in cotton crop and present potential carryover to rotational crops. The research aimed to evaluate the susceptibility of vegetal species to doses of trifloxysulfuron-sodium and pyrithiobac-sodium herbicides looking forward to selecting plants that may be used in monitoring low concentrations of these herbicides in soil. Two experiments were simultaneous carried out, in randomized entirely design, disposed in factorial scheme $4 \times 5$

\footnotetext{
${ }^{1}$ Recebido para publicação em 02/02/2011e na forma revisada em 29/03/2011.

${ }^{2}$ Discente do Curso de Pós-Graduação em Agronomia na área de Proteção de Plantas, NAPD/UEM, E-mail: naiara.guerra@hotmail.com;

${ }^{3}$ Professor Associado, Núcleo de Estudos Avançados em Ciência das Plantas Daninhas (NAPD/UEM), Dep. de Agronomia, Universidade Estadual de Maringá, Av. Colombo, 579087020 9000, Maringá- PR;

${ }^{4}$ Discente do curso de Agronomia da Universidade Estadual de Maringá-UEM.
} 
Guerra et al.

with four replicates, constituted by four species used as bioindicators (cucumber [Cucumis sativus], soybean [Glycine max], corn [Zea mays] and bean [Phaseolus vulgaris] and five herbicides doses (trifloxysulfuron-sodium $0 ; 0.94 ; 1.87 ; 3.75$ and $7.5 \mathrm{~g} \mathrm{ha}^{-1}$ and pyrithiobacsodium at $0 ; 8.75 ; 17.5 ; 35$ and $70 \mathrm{~g} \mathrm{ha}^{-1}$ ), applied in pre-emergence, before bioindicators sowing. Twenty-one days after application (DAA), plants were evaluated in relation to phytointoxication, height and dossel mass accumulation, calculating $\mathrm{I}_{50}$ (necessary dose for reducing $50 \%$ of analyzed variable), in order to compare species sensibility to herbicides. It was concluded that cucumber and corn behaved as the most sensitive species to trifloxysulfuron-sodium and pyrithiobac-sodium herbicides, showing potential for utilization in bioassays with these herbicides.

Key-words: Bioassays, ALS inhibitors, cucumber, herbicides behavior in soil.

\section{Introdução}

$\mathrm{O}$ trifloxysulfuron-sodium e pyrithiobac-sodium são herbicidas recomendados para o controle de plantas daninhas em pós-emergência da cultura do algodão (Freitas et al., 2006). Ambos inibem a atividade da enzima acetolactato sintetase (ALS), que é responsável por catalisar a primeira reação na produção dos aminoácidos de cadeia ramificada valina, leucina e isoleucina. Após a absorção, estes herbicidas são rapidamente translocados para a região de crescimento ativo das plantas, inibindo o seu desenvolvimento. As plantas suscetíveis acabam morrendo, devido à incapacidade de produzir os aminoácidos essenciais para o seu ciclo vital (Oliveira Jr., 2001).

Embora sejam predominantemente utilizados em pós-emergência, estes herbicidas também possuem atividade no solo (Veletza et al., 2005; Minton et al., 2008). Este fato pode acrescentar atividade residual à ação pósemergente destes herbicidas, mas, por outro lado, pode também representar risco potencial para espécies cultivadas em sucessão. Eventualmente, a persistência destes compostos pode também constituir em risco de contaminação do lençol freático (Brighenti et al., 2002).

Em relação ao trifloxysulfuron-sodium, mesmo sendo utilizado em baixas doses (em torno de 7,5 $\mathrm{g} \mathrm{ha}^{-1}$ ), o período de espera para o plantio de culturas sensíveis recomendado pelo fabricante é de, aproximadamente, oito meses a contar de sua aplicação (Rodrigues \& Almeida, 2005). Esse fato pode limitar sua utilização em áreas onde o agricultor cultiva, por exemplo, feijão no inverno (Procópio et al., 2004), milho e sorgo (Minton et al., 2008). O pyrithiobacsodium apresenta atividade biológica superior a 120 dias, o que também pode causar injúrias em culturas de sucessão como sorgo, milho, trigo e arroz (Veletza et al., 2005). No Brasil, estudos sobre o comportamento destes herbicidas no solo são escassos.

Segundo Inoue et al. (2002), dentre as técnicas analíticas que permitem a identificação e quantificação de resíduos de herbicidas no solo, destacam-se o uso de radioisótopos e a cromatografia líquida e gasosa. Alternativamente, podem-se utilizar espécies vegetais que apresentam alta sensibilidade ao herbicida de interesse (bioindicadores), sendo esta técnica mais acessível que as citadas anteriormente devido ao menor custo para sua realização (Silva et al., 2007; Nunes \& Vidal, 2009).

As vantagens dos bioensaios em estudos de comportamento de herbicidas no solo incluem, além da sua simplicidade e versatilidade, a alta sensibilidade (Groves \& Kent Forster, 1985), a detecção de metabólitos tóxicos que pode não ocorrer com métodos 
Guerra et al.

químicos altamente específicos (Brattain et al., 1983) e a habilidade de quantificar apenas a fração biologicamente ativa do herbicida, o que tem aplicabilidade direta em condições de campo (Appleby, 1985; Kotoula-Syka et al., 1993; Stork \& Hannah, 1996; Lima et al., 1999).

Andrade et al. (2010), comparando resultados de lixiviação de ametryn em colunas de solo, por bioensaios e cromatografia líquida de alta eficiência-CLAE, verificaram que em algumas regiões da coluna onde as plantas indicadoras apresentaram sintomas de intoxicação entre 20 e $40 \%$ não foi possível quantificar o herbicida por cromatografia. Provavelmente, pois o herbicida encontrava-se em concentração abaixo do limite de detecção do equipamento $\left(0,01 \mathrm{mg} \mathrm{L}^{-1}\right)$. E esta pequena quantidade de produto não detectada pela cromatografia pode causar injúrias em espécies sensíveis.

O presente trabalho teve como objetivo avaliar a susceptibilidade de espécies a doses dos herbicidas trifloxysulfuron-sodium e pyrithiobac-sodium, buscando selecionar plantas que possam ser utilizadas como bioindicadores em ensaios de comportamento destes herbicidas no solo.

\section{Material e métodos}

Os experimentos foram conduzidos durante o mês de outubro de 2009, em casa de vegetação. $\mathrm{O}$ solo utilizado como substrato apresentava textura franco-argilo-arenosa (66\% de areia; $32 \%$ de argila e $2 \%$ de silte). Com relação às características químicas, apresentou $\mathrm{pH}$ de $5,2 \mathrm{em} \mathrm{CaCl}_{2}, 3,68 \mathrm{cmol}_{\mathrm{c}} \mathrm{dm}^{-3}$ de $\mathrm{H}^{+}+\mathrm{Al}^{3+} ; 3,90 \mathrm{cmol}_{\mathrm{c}} \mathrm{dm}^{-3}$ de $\mathrm{Ca}^{+2} ; 1,60 \mathrm{cmol}_{\mathrm{c}}$ $\mathrm{dm}^{-3}$ de $\mathrm{Mg}^{+2} ; 0,45 \mathrm{cmol}_{\mathrm{c}} \mathrm{dm}^{-3}$ de $\mathrm{K}^{+} ; 4,30 \mathrm{mg}$ $\mathrm{dm}^{-3}$ de $\mathrm{P}$ e $7,75 \mathrm{~g} \mathrm{dm}^{-3}$ de C.

Foram conduzidos simultaneamente experimentos para o herbicida trifloxysulfuronsodium e para o pyrithiobac-sodium. Os tratamentos foram dispostos em esquema fatorial $4 \times 5$, sendo os fatores representados por quatro espécies utilizadas como bioindicadoras - pepino cv. Safira ${ }^{\circledR}$ (Cucumis sativus), soja cv. $\mathrm{V} \max ^{\circledR}$ (Glycine max), milho híbrido DKB $3904{ }^{\circledR}$ (Zea mays) e feijão cv. BRS Pérola ${ }^{\circledR}$ (Phaseolus vulgaris); e cinco doses dos herbicidas (trifloxysulfuron-sodium - 0; 0,94; 1,$87 ; 3,75$ e $7,5 \mathrm{~g} \mathrm{ha}^{-1}$ e pyrithiobac-sodium 0 ; 8,$75 ; 17,5 ; 35$ e $70 \mathrm{~g} \mathrm{ha}^{-1}$ ). O delineamento experimental utilizado para ambos os ensaios foi o inteiramente casualizado, com quatro repetições.

As unidades experimentais foram compostas por vasos de polietileno, com capacidade de $3 \mathrm{dm}^{3}$ de solo, nos quais foram semeadas 5 sementes de cada espécie, à profundidade de 1-2 cm. Após a semeadura, os vasos foram irrigados e depois de duas horas para procedeu-se à aplicação dos herbicidas. A aplicação foi realizada em 03/10/2009, com um pulverizador costal pressurizado com $\mathrm{CO}_{2}$, munido de quatro pontas XR110.02, mantido à pressão de trabalho de $2 \mathrm{kgf} \mathrm{cm}^{-2}$, o que resultou em um volume de calda de $200 \mathrm{~L} \mathrm{ha}^{-1}$. No momento da aplicação, a temperatura era de $22^{\circ} \mathrm{C}$ e a umidade relativa do ar era de $85 \%$.

Decorridos 21 dias após a aplicação dos herbicidas (DAA) avaliou-se a porcentagem de intoxicação das espécies utilizadas, por meio da escala visual, onde $0 \%$ corresponde à ausência de injúrias e $100 \%$ à morte das plantas, de acordo com recomendações da Sociedade Brasileira da Ciência das Plantas Daninhas (SBCPD, 1995). Nesta data, também foi avaliado o efeito dos herbicidas sobre a altura das plantas com auxílio de uma régua milimetrada. O número de plantas vivas por vaso foi anotado e, em seguida, foi colhida a parte aérea das mesmas. Esse material foi pesado em balança de precisão a fim de se obter a massa fresca. Com base nos dados obtidos, estabeleceu-se o $\mathrm{I}_{50}$ (dose necessária para redução de $50 \%$ da variável utilizada), a fim de comparar a sensibilidade das espécies. 
Guerra et al.

Os resultados de porcentagem de intoxicação, altura de plantas e de massa fresca da parte aérea dos bioindicadores foram submetidos à análise de variância $(\mathrm{p} \leq 0,05)$ e regressão. Os modelos de regressão foram escolhidos considerando-se a significância dos coeficientes de regressão e o significado biológico.

\section{Resultados e discussão}

Todas as espécies testadas mostraramse sensíveis ao herbicida trifloxysulfuronsodium. As plantas de pepino, soja e milho apresentaram sintomas caracterizados por limitação no porte, clorose no limbo foliar e necrose nos bordos foliares, sendo a intensidade proporcional à dose aplicada. Para o feijão foi observada redução no porte e leve clorose, principalmente na dose de 7,5 $\mathrm{g} \mathrm{ha}^{-1}$. $\mathrm{Na}$ Figura 1 estão apresentados os resultados da avaliação de fitointoxicação para pepino (a), soja (b), milho (c) e feijão (d), aos 21 DAA do herbicida trifloxysulfuron-sodium.

Dentre as espécies estudadas, observase que o pepino foi a que apresentou maior sensibilidade, pois a utilização de apenas $0,6 \mathrm{~g}$ ha $^{-1}$ foi suficiente para proporcionar fitointoxicação superior a $60 \%$. A partir da dose de $1,3 \mathrm{~g} \mathrm{ha}^{-1}$ os níveis de intoxicação se estabilizaram ficando entre 74 e $84 \%$. De acordo com a Tabela 1 , a utilização de $0,30 \mathrm{~g}$ $\mathrm{ha}^{-1}$ de trifloxysulfuron-sodium proporcionou intoxicação de $50 \%$ no pepino.

Soja, milho e feijão apresentaram aumento linear da fitointoxicação com aumento da dosagem de trifloxysulfuron-sodium, no entanto, para as duas primeiras espécies, para cada grama do herbicida, a intoxicação aumentou em aproximadamente $11 \%$, enquanto que para o feijão a taxa de aumento foi de $4,4 \%$. Dentro do intervalo de dosagens estudado, o feijão foi a espécie menos sensível ao trifloxysulfuron-sodium, com níveis máximos de intoxicação de 40\% (Tabela 1).

Quando o solo cultivado com milho recebeu a aplicação de $7,5 \mathrm{~g} \mathrm{ha}^{-1} \mathrm{de}$ trifloxysulfuron-sodium a intoxicação chegou a níveis próximos a $85 \%$, semelhante ao trabalho realizado em casa de vegetação por Minton et al., (2008), que verificaram intoxicação de $72 \%$.

Tabela 1. Valores de $\mathrm{I}_{50}$ para os herbicidas trifloxysulfuron-sodium e pyrithiobac-sodium.

\begin{tabular}{|c|c|c|c|c|c|c|}
\hline \multirow{3}{*}{$\begin{array}{l}\text { Espécie/ } \\
\text { Herbicida }\end{array}$} & \multicolumn{6}{|c|}{$\mathrm{I}_{50}{ }^{\mathrm{I}}$} \\
\hline & \multicolumn{6}{|c|}{$\left(\mathrm{g} \mathrm{ha}^{-1}\right)$} \\
\hline & \multicolumn{2}{|c|}{ Fitointoxicação } & \multicolumn{2}{|c|}{ Altura } & \multicolumn{2}{|c|}{ Massa fresca } \\
\hline Pepino & $\begin{array}{c}\text { Triflox. }^{2} \\
0,30\end{array}$ & $\begin{array}{c}\text { Pyrith. }^{3} \\
2,30\end{array}$ & $\begin{array}{c}\text { Triflox. } \\
2,53\end{array}$ & $\begin{array}{c}\text { Pyrith. } \\
2,64\end{array}$ & $\begin{array}{c}\text { Triflox. } \\
1,66\end{array}$ & $\begin{array}{c}\text { Pyrith. } \\
1,85\end{array}$ \\
\hline Soja & 4,33 & 22,80 & 4,41 & 59,40 & 2,44 & - \\
\hline Milho & 4,32 & 0,76 & 2,34 & 2,40 & 2,12 & 3,40 \\
\hline Feijão & $>7,50$ & $>70,00$ & $>7,50$ & $>70,00$ & $>7,50$ & $>70,00$ \\
\hline
\end{tabular}


Guerra et al.
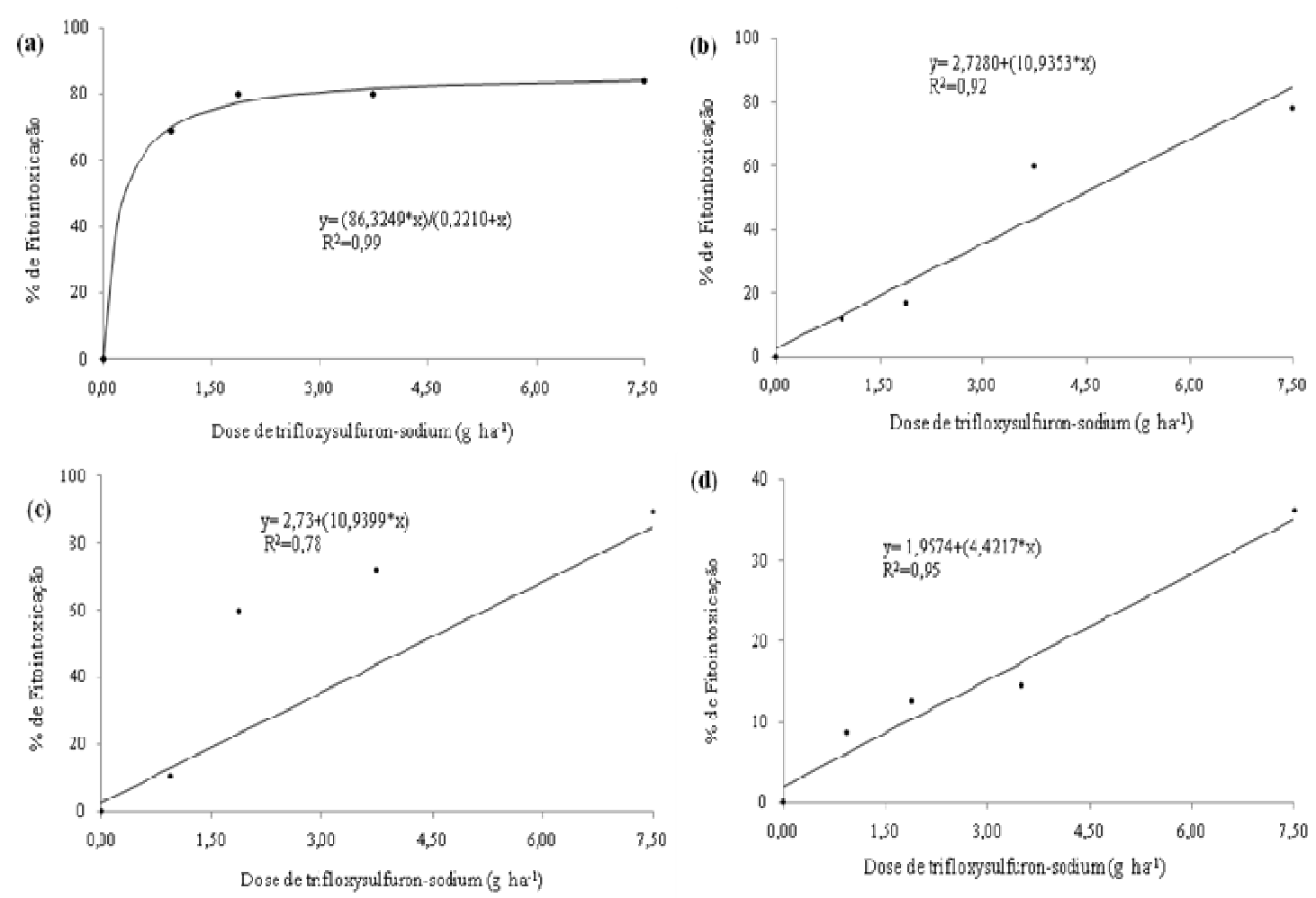

Figura 1. Efeito de doses de trifloxysulfuron-sodium na porcentagem de fitointoxicação das plantas de pepino (a), soja (b), milho (c) e feijão (d), aos 21 DAA.

O principal sintoma de fitointoxicação semelhante e suas respostas frente à presença do das plantas de pepino após a aplicação do herbicida no solo foram ajustadas por meio da herbicida pyrithiobac-sodium foi a intensa equação hiperbólica. Para essas espécies a redução do porte, independente da dosagem utilização de dosagens a partir de 20 e $12 \mathrm{~g} \mathrm{ha}^{-1}$, utilizada. Essas plantas não se desenvolveram e respectivamente, proporcionou sintomas severos permaneceram até o momento da coleta da parte de intoxicação (>90\%).

aérea (21 DAA) somente com suas folhas cotiledonares, enquanto que a testemunha nesta mesma época já possuía três folhas verdadeiras. Para o milho, estes sintomas caracterizaram-se por redução do porte, clorose internerval e necrose dos bordos foliares, variável em intensidade com a dosagem utilizada. A soja e o feijão apresentaram menor porte e leve clorose.

Para a soja e feijão, o aumento na dosagens causou incrementos lineares nos níveis de intoxicação, apresentando taxa de incremento de $1,2 \%$ e $0,49 \%$, respectivamente, para cada grama de pyrithiobac-sodium aplicada no solo. A análise desse parâmetro evidencia que, embora botanicamente relacionadas, as plantas de feijão e soja apresentam intensidades de

Os resultados de porcentagem de resposta variáveis, sendo o feijão mais tolerante fitointoxicação para pepino (a), soja (b), milho que a soja, com níveis de intoxicação inferiores (c) e feijão (d), aos 21 DAA de pyrithiobac- a $40 \%$ dentro da faixa de dosagens estudada. sodium encontram-se na Figura 2. As plantas de Comparando os resultados de $\mathrm{I}_{50}$ para pepino e milho apresentaram comportamento fitointoxicação dispostos na Tabela 1, verifica- 
Guerra et al.

se que as espécies que apresentaram maior milho, pepino, soja e feijão. sensibilidade foram em ordem decrescente,
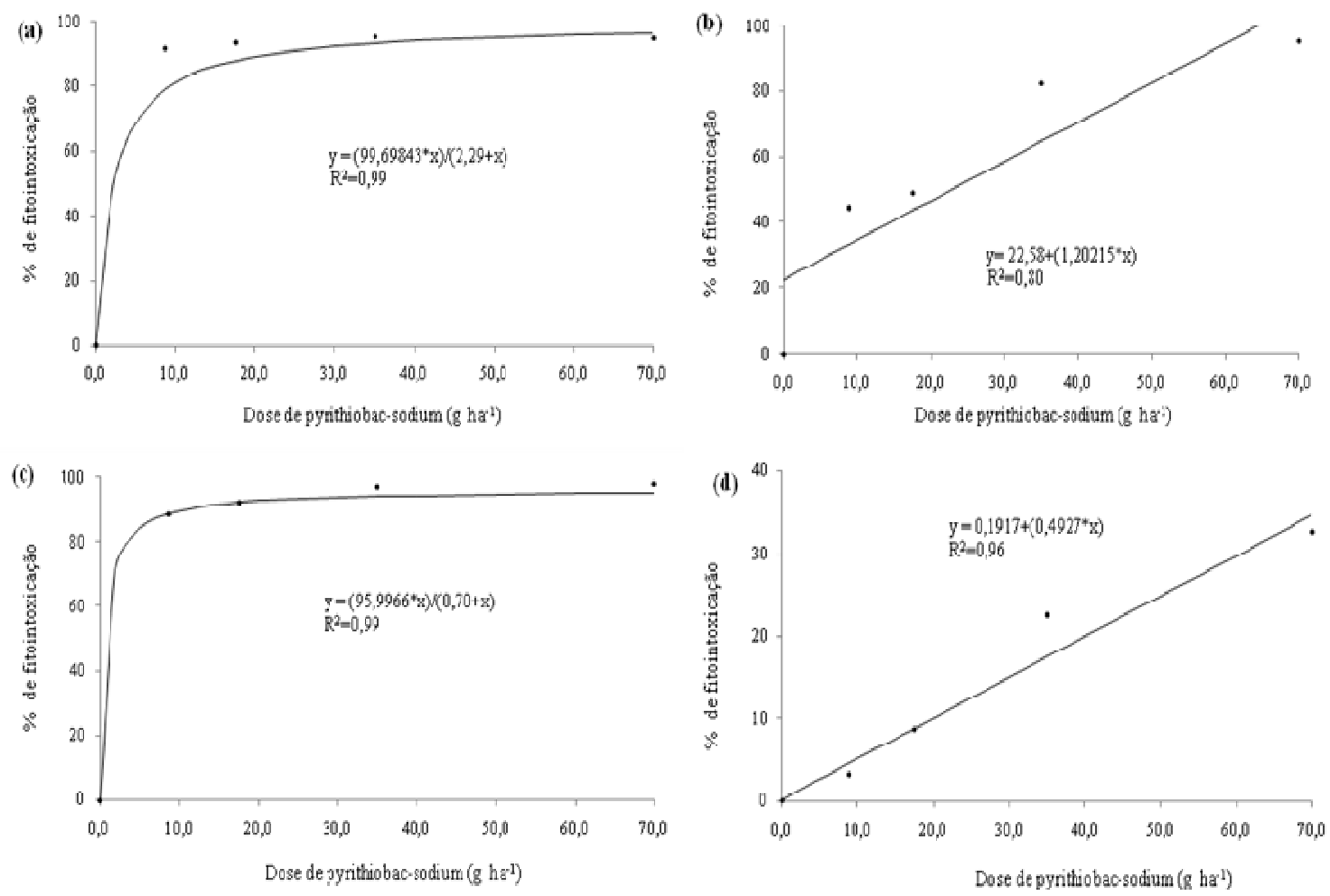

Figura 2. Efeito de doses de pyrithiobac-sodium na porcentagem de fitointoxicação das plantas de pepino (a), soja (b), milho (c) e feijão (d), aos 21 DAA.

Constatou-se efeito significativo $(\mathrm{p}<0,05)$ das doses de trifloxysulfuronsodium sobre a altura das plantas de pepino (a), soja (b), milho (c) e feijão (d). Para estas espécies o aumento da dosagem de trifloxysulfuron-sodium resultou em plantas com menor altura, porém a intensidade da resposta variou com a espécie testada (Figura 3). 
Guerra et al.
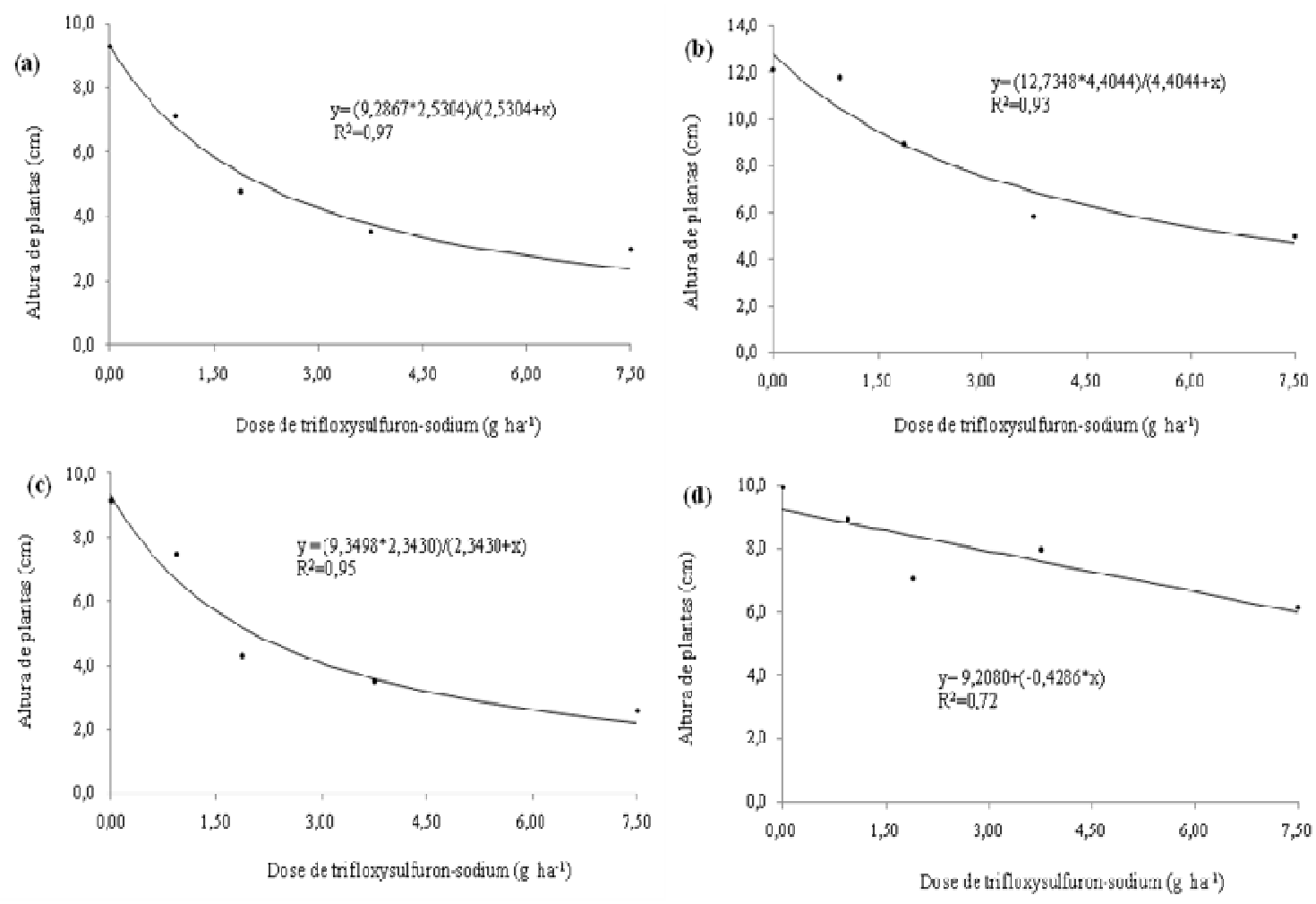

Figura 3. Efeito de doses de trifloxysulfuron-sodium sobre altura das plantas de pepino (a), soja (b), milho (c) e feijão (d), aos 21 DAA.

As espécies que apresentaram maior sensibilidade em relação a esta variável foram o pepino e o milho, para as quais a utilização de 2,53 e 2,34 $\mathrm{g} \mathrm{ha}^{-1}$ de trifloxysulfuronsodium, respectivamente, foram suficiente para reduzir em $50 \%$ a altura, enquanto que para a soja foi necessário $4,41 \mathrm{~g} \mathrm{ha}^{-1}$ para observar-se efeito semelhante (Tabela 1). Para o feijão, a redução na altura não foi expressiva, pois mesmo com 7,5 $\mathrm{g} \mathrm{ha}^{-1}$ deste herbicida não foi suficiente para reduzir em $50 \%$ a altura das plantas.
$\mathrm{O}$ efeito de pyrithiobac-sodium sobre a altura das espécies tratadas encontra-se na Figura 4. Foi possível constatar que o pepino (a) e o milho (c) foram as espécies mais sensíveis a esse herbicida, já que dosagens inferiores a 2,64 e 2,40 $\mathrm{g} \mathrm{ha}^{-1}$, respectivamente, foram suficientes para causar redução na altura de 50\% (Tabela 1). Quando semeado onde esse herbicida havia sido aplicado o pepino não emitiu folhas verdadeiras, ficando apenas com suas folhas cotiledonares, o que explica a intensidade de declive da curva. 
Guerra et al.
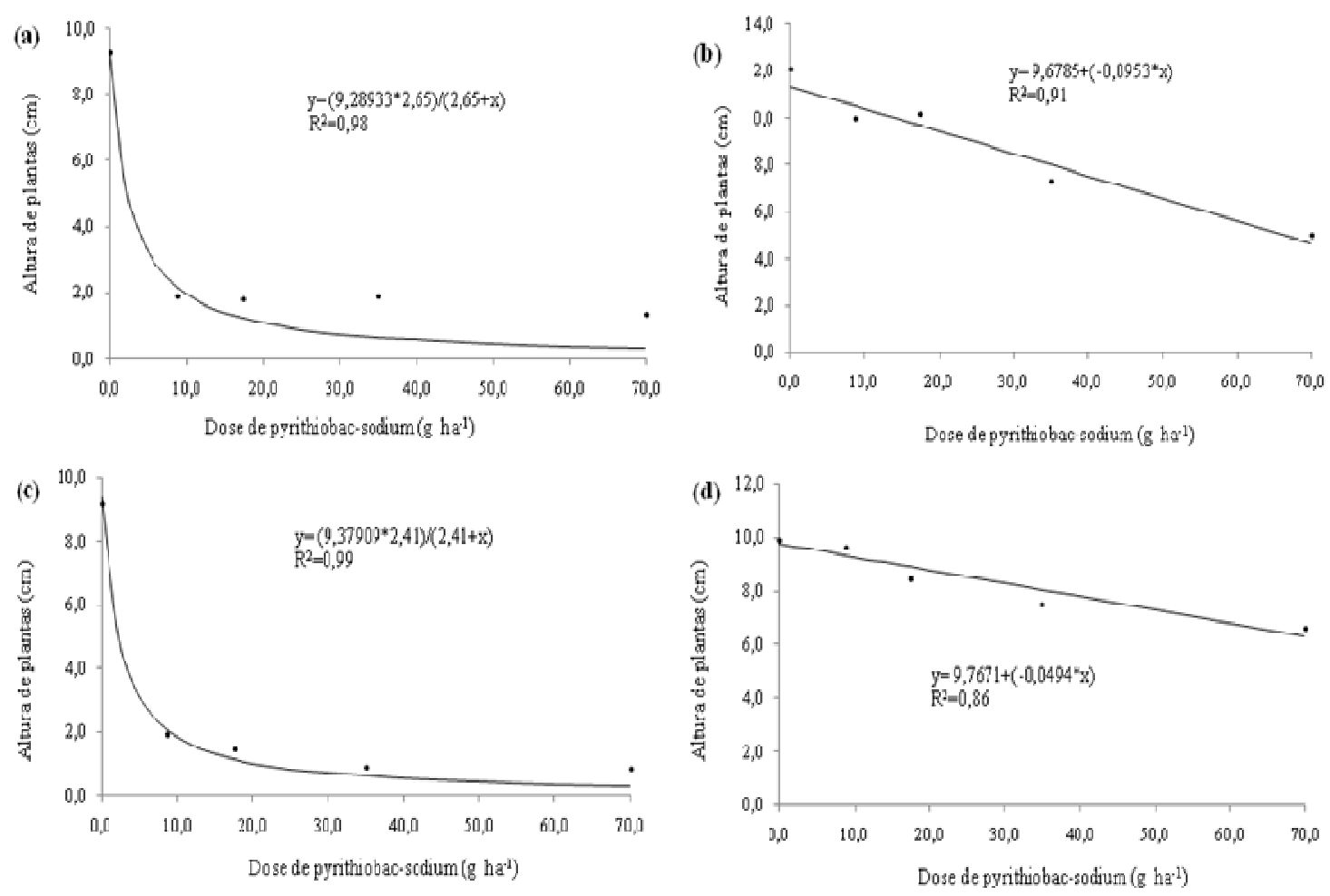

Figura 4. Efeito de doses de pyrithiobac-sodium sobre a altura das plantas de pepino (a), soja (b), milho (c) e feijão (d), aos 21 DAA.

Para a soja o aumento de uma unidade na dosagem aplicada do herbicida proporcionou redução de $0,09 \mathrm{~cm}$ na altura das plantas. Para o feijão esta redução foi menor $(0,05 \mathrm{~cm})$, evidenciando novamente que esta espécie não é muito sensível a este herbicida, não sendo, portanto, uma boa alternativa como bioindicador de baixas concentrações do produto no solo.

$\mathrm{Na}$ Figura 5 estão apresentados os dados de massa fresca da parte aérea para pepino (a), soja (b), milho (c) e feijão (d) aos 21 DAA do trifloxysulfuron-sodium. Analisando o $\mathrm{I}_{50}$ (Tabela 1), verifica-se que o feijão foi a espécie menos sensível ao trifloxysulfuron-sodium, pois nem mesmo a dosagem mais alta utilizada neste trabalho $(7,5$ $\mathrm{g} \mathrm{ha}^{-1}$ ) foi suficiente para causar $50 \%$ de inibição, provocando redução de apenas $23 \%$ em relação às plantas semeadas no solo sem herbicida. 
Guerra et al.
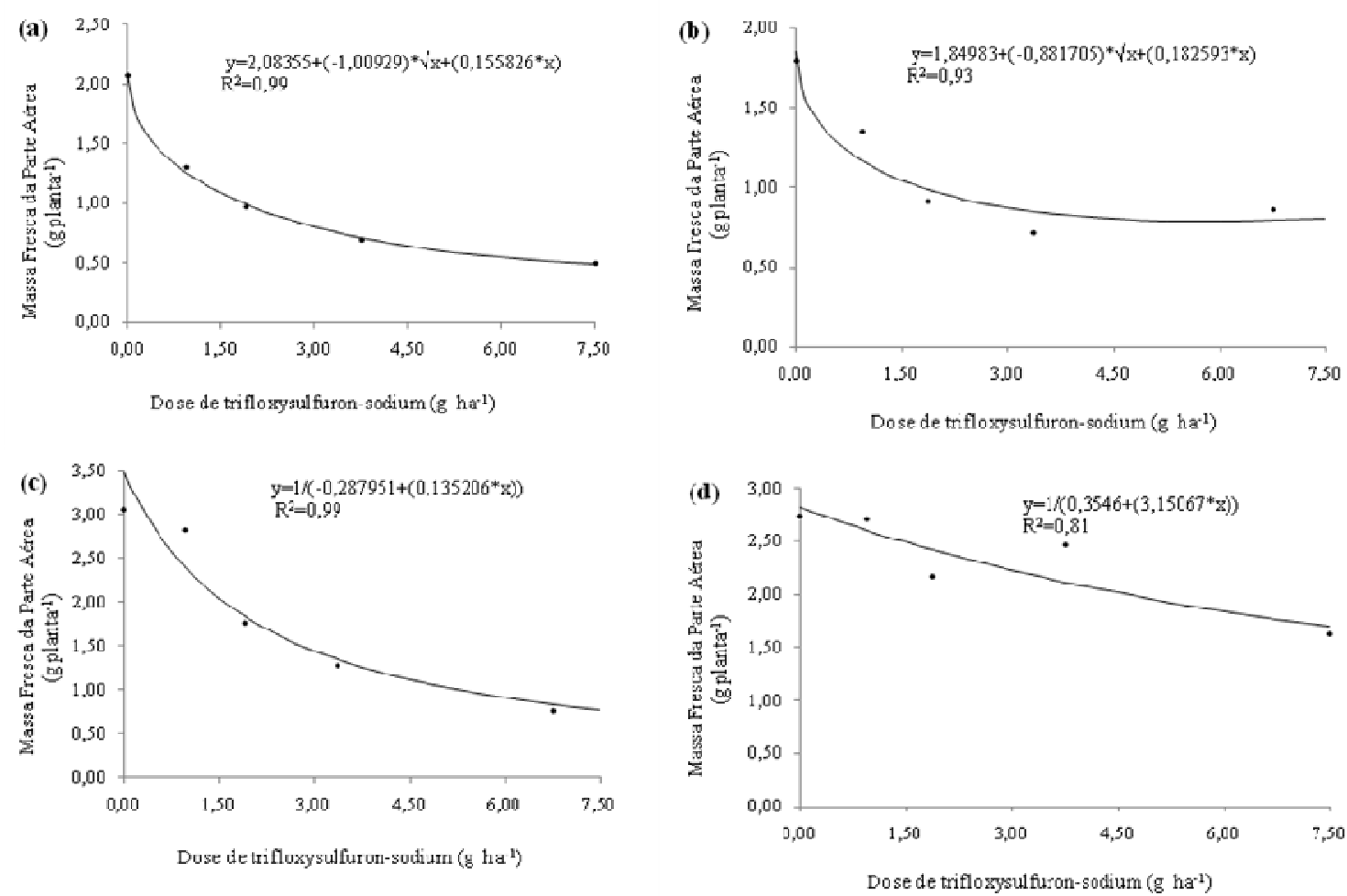

Figura 5. Efeito de doses de trifloxysulfuron-sodium na massa fresca da parte aérea de pepino (a), soja (b), milho (c) e feijão (d), aos 21 DAA.

As plantas de soja e milho apresentaram comportamento semelhante (Figura 4, b e c), demonstrando alta sensibilidade ao trifloxysulfuron-sodium, com $\mathrm{I}_{50}$ de 2,44 e 2,12, respectivamente (Tabela 1). A redução na massa fresca das plantas de milho chegou a $70 \%$ quando submetida à dosagem mais alta, corroborando com resultados de Minton et al. (2008), que verificaram redução de $84 \%$ na massa fresca da parte aérea do milho quando semeado no mesmo dia da aplicação de $7,5 \mathrm{~g}$ $\mathrm{ha}^{-1}$ de trifloxysulfuron-sodium, também em solo de textura franco-argilo-arenosa.

Porterfield \& Wilcut (2006) constataram, em condições de campo, que quando os híbridos de milho Pionner 3223 e SS797IT foram semeados em solo de textura arenosa no mesmo dia da aplicação de dosagens a partir de $3,75 \mathrm{~g} \mathrm{ha}^{-1}$ de trifloxysulfuron-sodium, houve redução no estande de $98 \%$ e $100 \%$, respectivamente.

Para o pepino, 1,66 $\mathrm{g} \mathrm{ha}^{-1}$ já foi suficiente para inibir em $50 \%$ o acúmulo de massa fresca, demonstrando ser, dentre as espécies estudadas, aquela com maior sensibilidade a baixas concentrações deste herbicida no solo.

Os resultados de massa fresca da parte aérea para pepino (a), soja (b), milho (c) e feijão (d) após a aplicação de doses de pyrithiobacsodium encontram-se na Figura 6. Para a soja não houve diferença significativa entre as dosagens, não havendo então $o$ ajuste de equação. $\mathrm{O}$ feijão apresentou a menor sensibilidade a este herbicida, apresentando redução máxima de $24 \%$ com a dosagem recomendada $\left(70 \mathrm{~g} \mathrm{ha}^{-1}\right)$. 
Guerra et al.
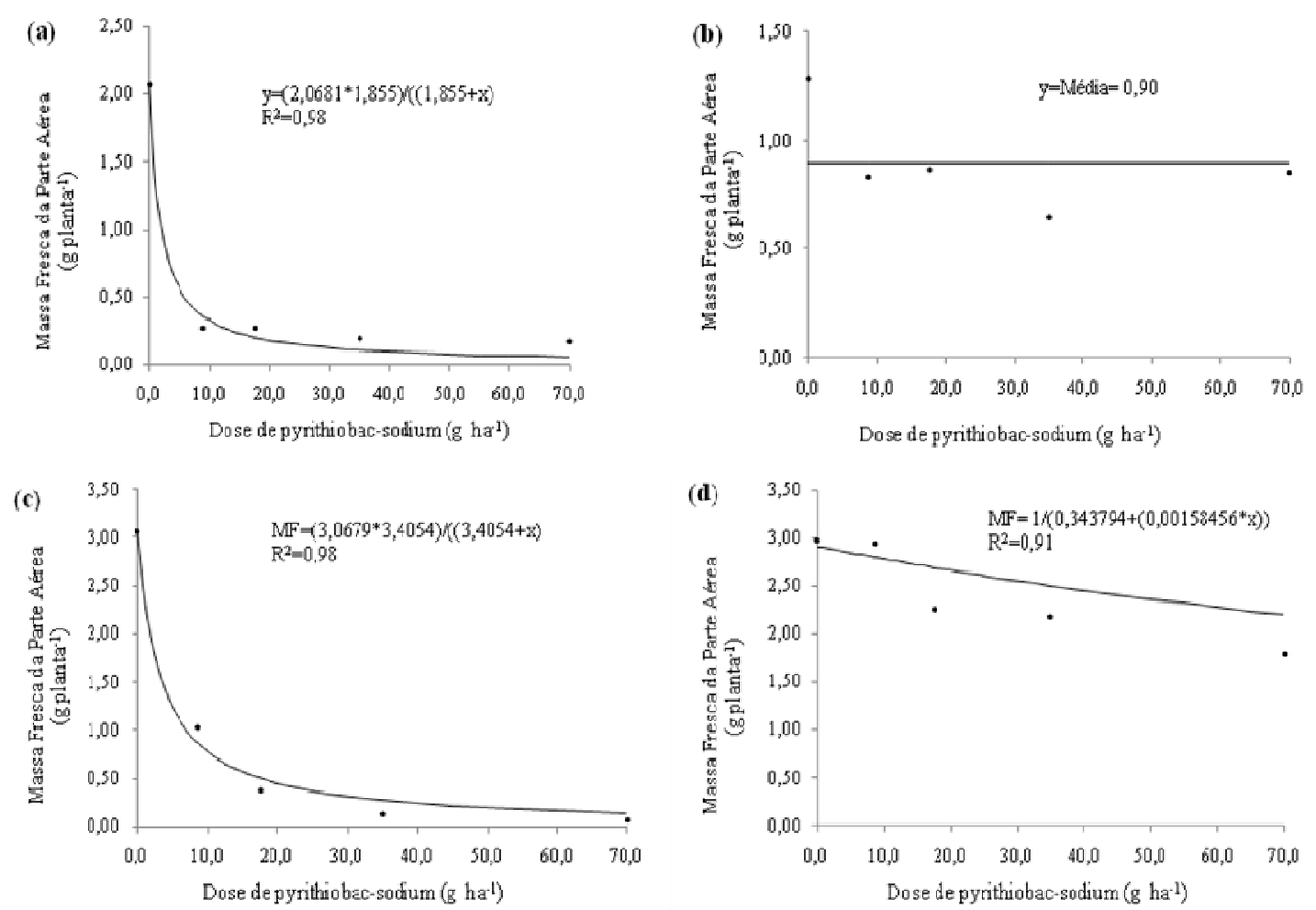

Figura 6. Efeito de doses de pyrithiobac-sodium na massa fresca da parte aérea de pepino (A), soja (B), milho (C) e feijão (D), aos 21 DAA.

O milho mostrou-se sensível ao pyrithiobac-sodium apresentando $\mathrm{I}_{50}$ de 3,40 . Veletza et al. (2005) também verificaram que o milho foi sensível a esse herbicida, e utilizando em bioensaios de comportamento deste herbicida no solo.

O pepino foi a espécie mais sensível ao pyrithiobac-sodium, uma vez que dosagens de $1,85 \mathrm{~g} \mathrm{ha}^{-1}$ já foram suficientes para reduzir em 50\% o acúmulo de massa fresca (Tabela 1), sendo esta 37 vezes inferior à recomendada.

Dentre as espécies estudadas, o pepino e o milho se mostraram bastante sensíveis aos herbicidas trifloxysulfuron-sodium e pyrithiobac-sodium podendo ser utilizadas em bioensaios com esses herbicidas. Ambas as espécies são utilizadas em ensaios com herbicidas inibidores de ALS. Pinto et al. (2009) utilizaram o milho como espécie bioindicadora do herbicida imazethapyr + imazapic, assim como Gazziero et al. (1997) para imazethapyr e imazaquin e Veletza et al. (2005) para pyrithiobac-sodium.

A utilização de pepino como espécie bioindicadora de herbicidas inibidores de ALS também é descrita em trabalhos publicados anteriormente. Vários autores utilizaram essa espécie em seus trabalhos como Inoue et al. (2000; 2002) e Gazziero et al. (1997) para imazethapyr e imazaquin, Monquero et al. (2010) para imazapic, Novo et al. (1997) para imazaquin, Nunes \& Vidal (2009) para chloransulan-methyl e imazaquin, Chiang \& Chiang (2001) para pyrazosulfuron-ethyl, bensulfuron-ethyl e imazosulfuron e Monquero et al. (2008) para mistura formulada de ametryn + trifloxysulfuron-sodium. 
Guerra et al.

\section{Conclusões}

O pepino e o milho comportaram-se como as espécies mais sensíveis aos herbicidas trifloxysulfuron-sodium e pyrithiobac-sodium, tendo grande potencial para utilização como plantas bioindicadoras em ensaios de comportamento destes herbicidas no solo.

\section{Referências}

ANDRADE, S.R.B. et al. Lixiviação do ametryn em Argissolo Vermelho-Amarelo e Latossolo Vermelho-Amarelo, com diferentes valores de pH. Planta Daninha, v.28, n.3, p.655-663, 2010.

APPLEBY, A.P. Factors in examining fate of herbicides in soil with bioassays. Weed Science., v.33, n.1, p.2-6, 1985.

BRATTAIN, R.L.; FAY, P.K.; LOCKERMAN, R.N. Comparision of bioassays for atrazine residue in soils. Agronomy Journal, v.75, n.1, p.192-194, 1983.

BRIGHENTI, A.M. et al. Persistência e fitotoxicidade do herbicida atrazine aplicado na cultura do milho sobre a cultura do girassol em sucessão. Planta Daninha, v.20, n.2, p.291-297, 2002.

CHIANG, Y.J.; CHIANG, M.Y. Biossay for detecting the residual activities of sulfonylurea herbicides in paddy water. Weed Science Bull. v.22, n.2, p.85-99, 2001.

FREITAS, R.S. et al. Manejo de plantas daninhas na cultura do algodoeiro com smetolachlor e trifloxysulfuron-sodium em sistema de plantio convencional. Planta Daninha, v.24, n.2, p.311-318, 2006.
GAZZIERO, D.L.P. et al. A. Persistência dos herbicidas imazaquin e imazethapyr no solo e os efeitos sobre plantas de milho e pepino. Planta Daninha, v.15, n.2, p.162-168, 1997.

GROVES, E.M.; KENT FORSTER, R.K. A corn (Zea mays L.) bioassay technique for measuring chlorsulfuron in three Saskatchewan soils. Weed Science, v.33, n.4, p.825-828, 1985.

INOUE, M.H. et al. Calagem e o potencial de lixiviação de imazaquin em colunas de solo. Planta Daninha, v.20, n.1, p.125-132, 2002.

INOUE, M.H. et al. Persistência da atividade biológica de imazaquin e imazethapyr aplicados em duas épocas do ano. Acta Scientiarum, v.22, n.4, p.993-997, 2000.

KOTOULA-SYKA, E. et al. Phytotoxicity and persistence of chlorsulfuron, metsulfuronmethyl, triasulfuron and tribenuron-methyl in three soils. Weed Research. v.33, n.5, p.355367, 1993.

LIMA, R.O. et al. Comportamento do herbicida flumioxazin em solo com diferentes doses de calcário. Revista Ceres, v.46, n.268, p.607613, 1999.

MINTON, B.W.; MATOCHA, M.A.; SENSEMAN, S.A. Rotational crops response to soil applied trifloxysulfuron. Weed Technology, v.22, n.3, p.425-430, 2008.

MONQUERO, P.A. et al. Lixiviação e persistência dos herbicidas sulfentrazone e imazapic. Planta Daninha, v.28, n.1, p.185195, 2010.

MONQUERO, P.A. et al. Potencial de lixiviação de herbicidas no solo submetidos a diferentes simulações de precipitação. Planta Daninha, v.26, n.2, p.403-408, 2008.

NOVO, M.C.S.S. et al. Persistência de imazaquin em latossolo roxo cultivado com soja. Planta Daninha, v.15, n.1, p.30-38, 1997. 
Guerra et al.

NUNES, A.L.; VIDAL, R.A. Seleção de plantas quantificadoras de herbicidas residuais. R. ecotoxicol. e meio ambiente, v.19, n.1, p.19-28, 2009.

OLIVEIRA JR., R.S. In:Mecanismos de Ação de Herbicidas. OLIVEIRA JR., R.S.; CONSTANTIN, J. (Coord.) Plantas daninhas e seu manejo. Guaíba: Agropecuária, 2001, p. 209-260.

PINTO, J.J.O. et al. Milho (Zea mays) como espécie bioindicadora da atividade residual de (imazethapyr+imazapic). Planta Daninha, v.27, n.esp., p.1005-1014, 2009.

PORTERFIELD, D.; WILCUT, J.W. Corn (Zea mays L.) response to trifloxysulfuron. Weed Technology, v.20, n.1, p.81-85, 2006.

PROCÓPIO, S.O. et al. Potencial de espécies vegetais para a remediação do herbicida trifloxysulfuron-sodium. Planta Daninha, v.23, n.1, p.09-16, 2004.
RODRIGUES, B.N.; ALMEIDA, F.S. Guia de herbicidas. 5 ed. Londrina, PR: 2005. 591 p.

SILVA, A.A.; VIVIAN, R.; OLIVEIRA JR., R.S. Herbicidas: comportamento no solo. In: SILVA, A.A.; SILVA,J. F. Tópicos e manejos de plantas daninhas. Viçosa, 2007. p.198-248. SOCIEDADE BRASILEIRA DA CIÊNCIA DAS PLANTAS DANINHAS. Procedimentos para instalação, avaliação e análise de experimentos com herbicidas. Londrina: SBCPD, 1995. 42p.

STORK, P.; HANNAH, M.C.A bioassay method for formulation testing and residue studies of sulfonylurea and sulfonanylide herbicides. Weed Research, v.36, n.3, p.271281, 1996.

VELETZA, V.G. et al. Activity, adsorption, mobility and field persistence of pyrithiobac in three soils. Weed Science, v.53, n.2, p.212$219,2005$. 